Article

\title{
Quantum Chemical and Kinetic Study on Polychlorinated Naphthalene Formation from 3-Chlorophenol Precursor
}

\author{
Fei Xu, Xiangli Shi and Qingzhu Zhang * \\ Environment Research Institute, Shandong University, Jinan 250100, China; \\ E-Mails: xufei@sdu.edu.cn (F.X.); 123songchuan@163.com (X.S.) \\ * Author to whom correspondence should be addressed; E-Mail: zqz@sdu.edu.cn; \\ Tel.: +86-531-8836-4435; Fax: +86-531-8836-1990.
}

Received: 31 July 2015 / Accepted: 27 August 2015 / Published: 31 August 2015

\begin{abstract}
Polychlorinated naphthalenes (PCNs) are the smallest chlorinated polycyclic aromatic hydrocarbons (Cl-PAHs) and are often called dioxin-like compounds. Chlorophenols (CPs) are important precursors of PCN formation. In this paper, mechanistic and kinetic studies on the homogeneous gas-phase formation mechanism of PCNs from 3-CP precursor were investigated theoretically by using the density functional theory (DFT) method and canonical variational transition-state theory (CVT) with small curvature tunneling contribution (SCT). The reaction priority of different PCN formation pathways were disscussed. The rate constants of crucial elementary steps were deduced over a wide temperature range of 600-1200 K. The mechanisms were compared with the experimental observation and our previous works on the PCN formation from 2-CP and 4-CP. This study shows that pathways ended with $\mathrm{Cl}$ elimination are favored over those ended with $\mathrm{H}$ elimination from the 3-CP precursor. The formation potential of $\mathrm{MCN}$ is larger than that of DCN. The chlorine substitution pattern of monochlorophenols has a significant effect on isomer patterns and formation potential of PCN products. The results can be input into the environmental PCN controlling and prediction models as detailed parameters, which can be used to confirm the formation routes of PCNs, reduce PCN emission and establish PCN controlling strategies.
\end{abstract}

Keywords: 3-chlorophenol; polychlorinated naphthalene; formation mechanism; rate constants; density functional method 


\section{Introduction}

Chlorinated polycyclic aromatic hydrocarbons (Cl-PAHs) are PAH derivatives and have recently attracted considerable public concern because of their widespread occurrence [1,2], high toxicity $[3,4]$, and close association with particle formation in urban air $[2,5,6]$. Compared with their parent PAHs, Cl-PAHs have lower vapor pressures, higher octanol-water partition coefficient values, and even highter mutagenicity and toxicixty [7-9]. Main sources of Cl-PAHs include chlorinated tap waters, combustion of chlorine-containing materials, wastewater of pulp and paper mills, photochemical reactions of PAHs, automobile exhaust, and municipal solid waste (MSW) incineration [1,10-16]. Polychlorinated naphthalenes (PCNs), which are often called dioxin-like compounds, are the smallest Cl-PAHs. The mechanism of PCN formation will represent growth reactions for larger Cl-PAHs. PCN are a group of 75 possible congeners consisting of naphthanlene substituted with 1-8 chlorine atoms. The structures of

\section{PCNs are}

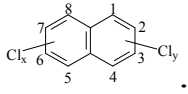

Chlorophenols (CPs) are among the most abundant aromatic compounds found in MSW exhaust gases [17]. CPs are an important class of serious environmental contaminants because of their toxicity, carcinogenicity, bioaccumulation, and considerable persistence. Due to the different substitution pattern of phenol, CPs have 19 isomers. Among them, monochlorophenols (MCPs) are some of the most important contaminants existed in the environment which were used in several industrial processes and agricultures $[18,19]$. It was reported that the three MCP have similar toxicity, but 3-Chlorophenol (3-CP) has a the slowest degradation rate and the longest residence time among them [20]. 3-CP is used as the intermediate products of the coal and petroleum refinery industries, and raw materials to further synthesize pharmaceutical products, pesticides, solvents, textile additives, and specialty chemicals [21].Contact and breathing 3-CP can irritate and burn the skin, eyes, nose, throat, and lungs causing coughing, wheezing, and shortness of breath [22]. High exposure can cause headache, dizziness, fatigue, restlessness, muscle weakness, tremors, seizures, coma, and even death [22]. 3-CP is on the Hazadous Substance list of Department of Traspotation (DOT), New Jersey Department of Environmental Protection(DEP) and Environmental Protection Agency(EPA) [22].

PCN formation contains gas-phase homogeneous reactions and heterogeneous metal-mediated reactions on fly ash from precursors. Numbers studies reported that PCN are formed unintentionally from industrial thermal processes and incomplete combustion from municipal solid waste incineration as byproducts, along with other halogenated aromatic compounds, such as PCBs, PCDDs, and PCDFs in combustion exhaust gas [23-31]. Among different precursors, CPs play a crucial role in the formation of PCNs [26-29,32-34]. In combustion and thermal processes, CPs can lose phenoxyl-hydrogen to form chlorophenoxy radicals (CPRs). In 1975, Cypres and Betterns first reported the PCN formation from phenol [35]. Since that time, many researches reported the naphthalene formation from phenol via dimerization of cyclopentadienyl (CPDyl) radicals, which were produced via CO loss from phenol [36-38]. CPDyl radicals have been shown to play important role in the PAH growth mechanisms at high temperature $[39,40]$. According to this naphthalene formation mechanism, previous studies predicted PCN formation occur via condensation of two chlorinated cyclopentadienyl radicals (chloro-CPDyl $-\mathrm{Cl}$

) produced by CO loss of CPRs [26-29], based on the naphthalene formation mechanism 
proposed by Melius [41]. Recombination of two chloro-CPDyl radicals to form chlorinated dihydrofulvene $\left({ }^{\mathrm{Cl}}\right.$ ), followed by rearrangement and $\mathrm{H} / \mathrm{Cl}$ elimination can result in the PCN's formation [25-28]. In this mechanism, 2-CP, 3-CP, and 4-CP were speculated to form the same chloro-CPDyl radical and exactly the same PCN isomer patterns [26-29,32,33]. However, this hypothesis was experimentally opposed by Kim via obtaining completely different PCN isomer distributions from 2-CP, 3-CP, and 4-CP (Scheme 1) [32,33]. For example, in Kim's experiment, 2-CP produced mostly 1-MCN and 1,5/1,6/1,7-DCNs; 4-CP produced mostly 2-MCN and 2,6/2,7-DCNs; 3-CP produced nearely equivalent 1-MCN and 2-MCN, and nearly equal 1,5/1,6/1,7-DCNs and 2,6/2,7-DCNs [32,33]. In addition, this hypothesis was, again, denied by some experimental observations in thermal processes that the correlation between PCN and PCDF isomer distributions or mass concentrations is more closer than that between PCN and PCDD, which indicate a new PCN formation mechanism more similar with PCDF formation than PCDD [30,31,42-46]. In this situation, Kim proposed an alternative PCN formation mechanism based on experimental results [32-34]; in his scheme, PCNs are formed via carbon-carbon coupling at ortho-sites of CPR pairs, resulting in an intermediate chlorinated o,o'-dihydroxybiphenyl (chloro-DOHB) [32-34]. Chlorinated dihydrofulvene are formed from chloro-DOHB by two CO loss and ring close steps, not by condensation of two chloro-CPDyl radicals [32-34]. Both PCDF and PCN can be produced from chloro-DOHB by different tautomerization steps [32-34].

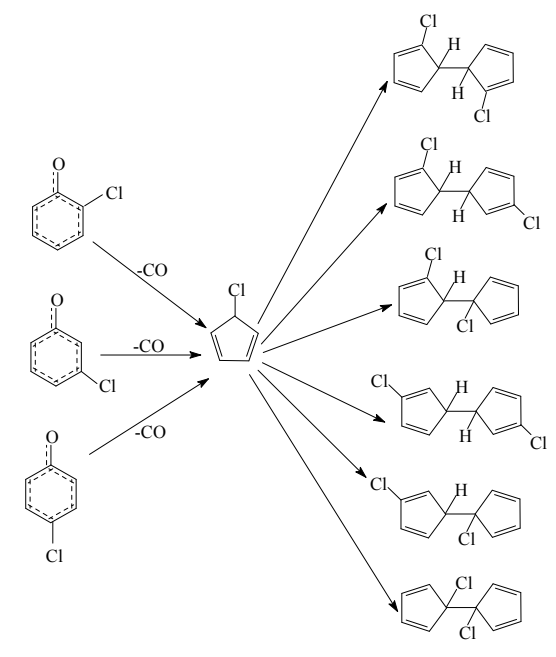

Scheme 1. The hypothesis on chlorinated dihydrofulvene formation from three monochlorophenols.

Due to the high toxicity of PCNs and the lack of efficient detection schemes for intermediate radicals, the specific formation mechanism of PCNs from CPs remains unclear. Our previous studies have systematically investigated the homogeneous gas-phase formation mechanism of PCNs from 2-CP and 4-CP precursors [47,48]. As a ongoing study of this field, it is important to continue study the PCN formation mechanism from 3-CP in order to compare the contributions and effects of ortho-, meta-, and para-chlorine of monochlorophenol on the formation potential and isomer distributions of $\mathrm{PCN}$ products. Kim only gave a simple mechanism of PCN formation from 3-CP which loses numbers of important intermediates and can not explain some of his experimental observations [32,33]. For example, the mechanism predicted by Kim can not give reasonable explanations on the experimental results that the amont of MCN is significantly larger than that of DCN [32,33]. In addition, only trace amounts of 
1,8-DCN were experimentally observed from 3-CP, whereas the 1,8-DCN formation routes are competitive with 1,5-/1,6-/1,7-DCNs in Kim's speculated mechanism [32,33]. Moreover, Yang also studied the PCN formation from 3-CP [27]. In Yang's study the main MCN product from 3-CP is 2-MCN, wheras in Kim's results 3-CP produced approximately equal amounts of 1-MCN and 2-MCN [32,33]. Furthermore, Kim mentioned in his paper that $\mathrm{H} / \mathrm{Cl}$ migration in the cyclopentadiene ring of chlorinated dihydrofulvene [32,33] to ortho-carbon occurs first before ortho-carbon $\mathrm{H} / \mathrm{Cl}$ elimination. However, the $\mathrm{H}$ or $\mathrm{Cl}$ atoms may be abstracted directly without $\mathrm{H}$ or $\mathrm{Cl}$ migration, which need to be studied further. Thus, more detailed and specific mechanisms on PCN formation from 3-CP precursor need to be proposed to solve all the contradictions above.

This study is carried out for three objectives. The first aim of this paper is to deeply investigate the reaction mechanism on the PCN formation from 3-CP precursor, using a comprehensive quantum calculation. Quantum chemical calculation is a useful method to establish the pathway feasibility and confirm the product priority, especially for the highly toxic compounds. A second motivation for this work is to evaluate the rate constants of the elementary reactions involved in the PCN formations over a wide temperature range of $600-1200 \mathrm{~K}$. The absence of the kinetic parameters prevent to further improve and optimize PCN formation models. The third purpose is to discuss the effect of the chlorine substitution pattern of CPs on isomer patterns and formation potential of PCNs.

\section{Results and Discussion}

The formation of CPRs from CPs is the initial and key step in the formation of PCNs. In combustion and thermal processes, CPRs can be produced through loss of the phenoxyl-hydrogen via unimolecular cleavage of the $\mathrm{O}-\mathrm{H}$ bond or abstracted by the active radicals $\mathrm{H}, \mathrm{OH}, \mathrm{O}\left({ }^{3} \mathrm{P}\right)$, and $\mathrm{Cl}$. The potential barriers $(\Delta E)$ and the reaction heats $(\Delta H)$ of 3-CP phenoxyl-hydrogen cleavage and abstraction by $\mathrm{H}$, $\mathrm{OH}, \mathrm{O}\left({ }^{3} \mathrm{P}\right)$, and $\mathrm{Cl}$ were calculated at the MPWB1K/6-311+G(3df,2p) level as follows. The $\mathrm{H} / \mathrm{OH}$ abstraction data were cited by the previous studies of our group [49,50]. All the abstraction steps are strongly exothermic:

$$
\begin{aligned}
& 3-\mathrm{CP}+\mathrm{H} \rightarrow 3-\mathrm{CPR}+\mathrm{H}_{2} \Delta E=12.51 \mathrm{kcal} / \mathrm{mol} \Delta H=-12.94 \mathrm{kcal} / \mathrm{mol} \\
& 3-\mathrm{CP}+\mathrm{OH} \rightarrow 3-\mathrm{CPR}+\mathrm{H}_{2} \mathrm{O} \Delta E=0.17 \mathrm{kcal} / \mathrm{mol} \Delta H=-27.81 \mathrm{kcal} / \mathrm{mol} \\
& 3-\mathrm{CP}+\mathrm{O}\left({ }^{3} \mathrm{P}\right) \rightarrow 3-\mathrm{CPR}+\mathrm{OH} \Delta E=8.20 \mathrm{kcal} / \mathrm{mol} \Delta H=-12.04 \mathrm{kcal} / \mathrm{mol} \\
& 3-\mathrm{CP}+\mathrm{Cl} \rightarrow 3-\mathrm{CPR}+\mathrm{HCl} \Delta E=-5.87 \mathrm{kcal} / \mathrm{mol} \Delta H=-15.66 \mathrm{kcal} / \mathrm{mol}
\end{aligned}
$$

\subsection{Formation of Chloro-Dihydrofulvene from Dimerization of 3-CPRs}

Formation of PCNs from dimerization of 3-CPRs contains two progressions: formation of chloro-dihydrofulvlene (IM5, IM10 and IM18) from dimerization of 3-CPRs (Figure 1) and formation of PCNs from subsequent reactions of chloro-dihydrofulvene (Figures 2-6). The configurations of the transition states involved in one typical route of PCN formation are depicted in Figure S1 of the Suporting Information. Imaginary frequencies, zero point energies, and total energies for all the transition states involved in the formation of PCNs from dimerization of 3-CPRs are shown in Table S1 of the Suporting Information. Cartesian coordinates for the reactants, intermediates, transition states, and products involved in this paper are revealed in Tables S2 and S3. 


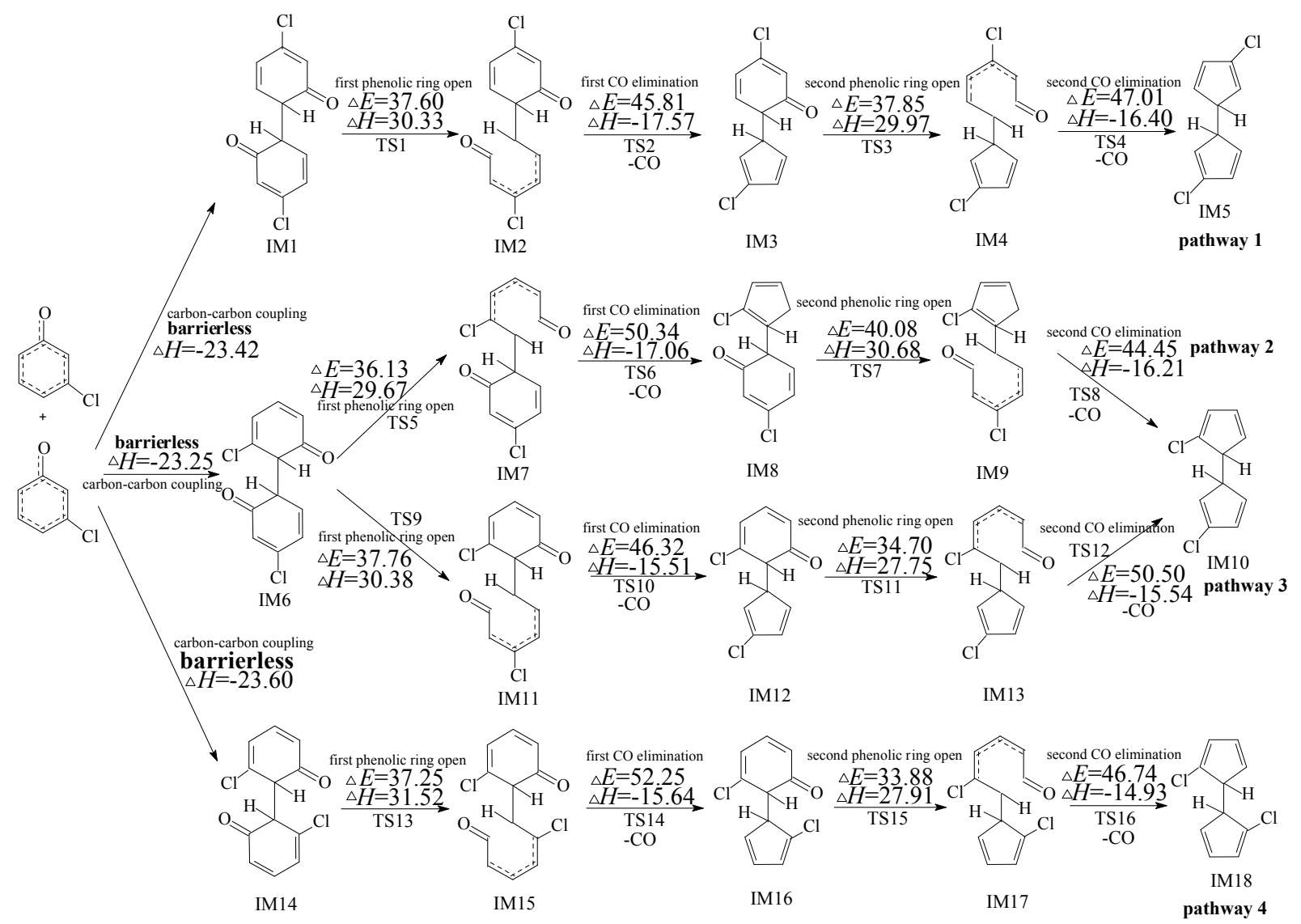

Figure 1. Chlorinated dihydrofulvene formation routes embedded with the potential barriers $\Delta E$ (in $\mathrm{kcal} / \mathrm{mol})$ and reaction heats $\Delta H$ (in $\mathrm{kcal} / \mathrm{mol})$ from dimerization of 3-CPRs. $\Delta H$ is calculated at $0 \mathrm{~K}$.

Figure 1 demonstrates the first progress of PCN formation from dimerization of 3-CPRs, e.g., formation of chloro-dihydrofulvene. As shown in Figure 1, three chloro-dihydrofulvenes (IM5, IM10, and IM18) from four possible formation pathways (pathways 1-4) are proposed from the dimerization of 3-CPRs. The potential barriers $(\Delta E)$ and reaction heats $(\Delta H)$ are calculated at the MPWB1K/ $6-311+\mathrm{G}(3 \mathrm{df}, 2 \mathrm{p}) / / \mathrm{MPWB} 1 \mathrm{~K} / 6-31+\mathrm{G}(\mathrm{d}, \mathrm{p})$ level. All the four pathways are similar, involving five elementary steps: (1) carbon-carbon coupling; (2) first phenolic ring open; (3) first CO elimination; (4) second phenolic ring open; and (5) second $\mathrm{CO}$ elimination. There are three carbon-carbon coupling modes in Figure 1, resulting in the formation of intermediates IM1, IM6, and IM14. Different from dimerization of 2-CPRs, all the three carbon-carbon coupling modes are the coupling of two carbon(hydrogen)-centered radical mesomers $(\mathrm{CH} / \mathrm{CH}$ for short), because all the two ortho-positions in 3-CPR are $\mathrm{H}$ atoms. All the three $\mathrm{CH} / \mathrm{CH}$ coupling are barrierless and strongly exothermic. The first/second $\mathrm{CO}$ elimination step is a concerted reaction with a five-member ring form simultaneously. Comparing the four chloro-dihydrofulvene formation pathways, the barrier of each step in pathway 1 is lower than $50 \mathrm{kcal} / \mathrm{mol}$, whereas one step has a potential barrier about $50 \mathrm{kcal} / \mathrm{mol}$ in pathway 2 and pathway 3, and one step has barrier higher than $52 \mathrm{kcal} / \mathrm{mol}$ in pathway 4 . Thus, pathway 1 is the most feasible energetically, and pathway 4 is the most difficult to occur. However, at high temperature conditions in combustion and thermal processes, these potential barriers are easily overcome. Thus, all pathways 1-4 are energetically feasible. 


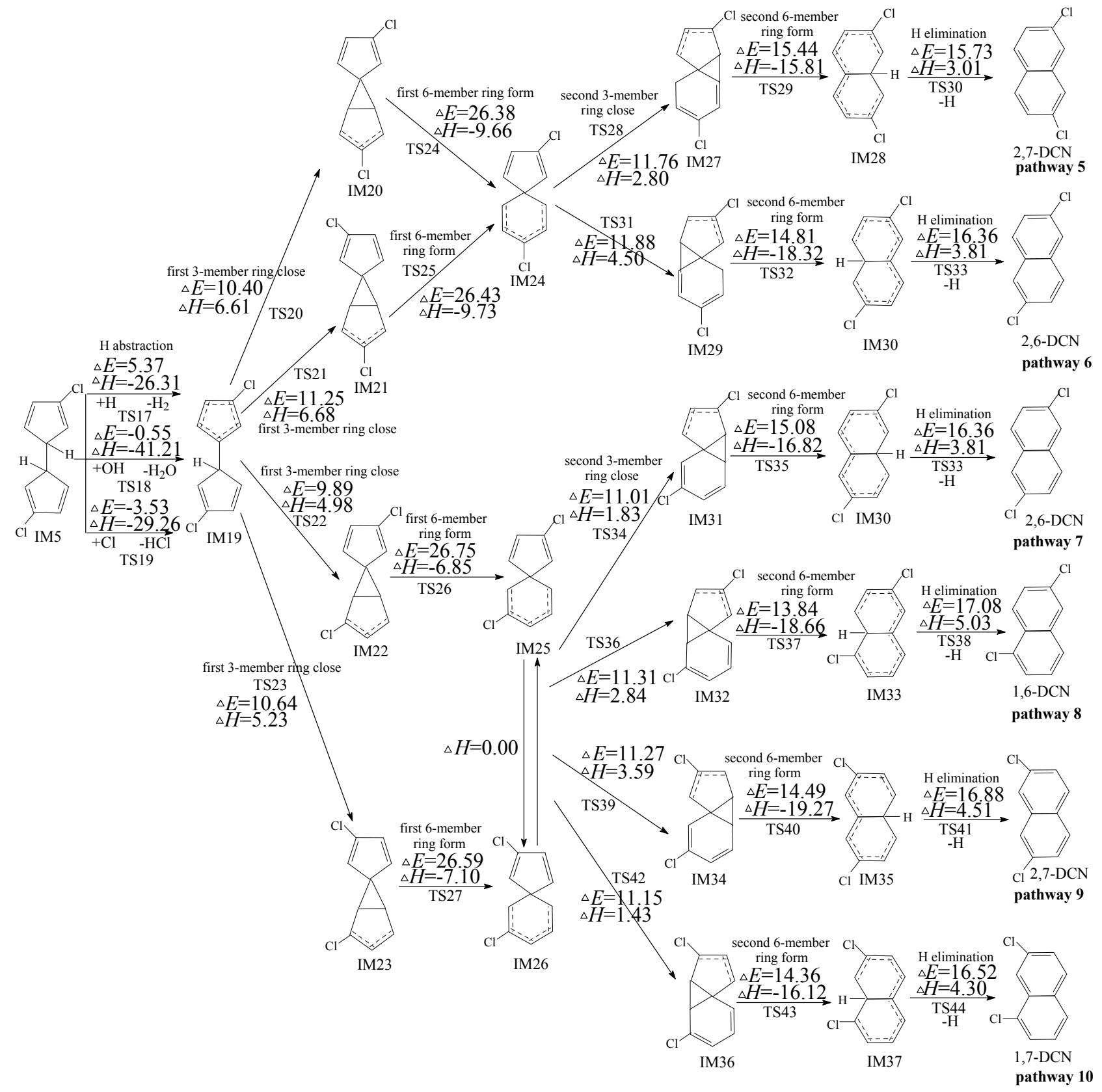

Figure 2. PCN formation routes embedded with the potential barriers $\Delta E$ (in $\mathrm{kcal} / \mathrm{mol}$ ) and reaction heats $\Delta H$ (in $\mathrm{kcal} / \mathrm{mol})$ from IM5. $\Delta H$ is calculated at $0 \mathrm{~K}$.

\subsection{Formation of PCNs from Subsequent Reactions of IM5}

Four PCNs products (1,6-/1,7-DCNs and 2,6-/2,7-DCNs) from six possible reaction pathways (pathways 5-10) are proposed for the subsequent reactions of IM5 in Figure 2. In Figure 2, pathways 5-10 are similar, involving the following six elementary steps: (1) H abstraction; (2) first three-member ring close; (3) first six-member ring form; (4) second three-member ring close; (5) second six-member ring form; and (6) $\mathrm{H}$ elimination. The $\mathrm{H}$ atom can be abstracted by $\mathrm{H}, \mathrm{OH}$, and $\mathrm{Cl}$ radicals with low potential barriers and quite negative reaction heats. $\mathrm{H}$ abstraction of IM5 by $\mathrm{OH}$ and $\mathrm{Cl}$ radicals exhibit negative barriers due to the existence of prereactive complexes. The first six-member ring form step requires crossing a high barrier and is the rate-determining step for pathways 5-10. IM25 and IM26 are 
enantiomers that produce the same subsequent intermediate (IM31, IM32, IM34, and IM36). From Figure 2, pathway 5 and pathway 6 have the same rate-determining step with the potential barriers 26.38 and $26.43 \mathrm{kcal} / \mathrm{mol}$, whearas pathways $7-10$ have the same rate-determining step with the potential barriers 26.75 and $26.59 \mathrm{kcal} / \mathrm{mol}$. The potential barriers of the rate-determining steps for all the six pathways are close, i.e., pathways 5-10 are competitive. Thus all the PCN formation pathways in Figure 2 are feasible, resulting in the formation of 1,6-/1,7-DCNs and 2,6-/2,7-DCNs. Among the four DCN formation pathways, 1,6-/1,7-DCN are obtained only via two pathways (pathways 8 and 10), whereas 2,6-/2,7-DCN are obtained via four pathways (pathways 5, 6, 7, and 9). Thus, the formation potential of 2,6-/2,7-DCNs is larger than that of 1,6-/1,7-DCNs. The main PCN products from subsequent reactions of IM5 are 2,6-/2,7-DCNs.

\subsection{Formation of PCNs from Subsequent Reactions of IM10}

Owning to the asymmetry of IM10, the subsequent reactions of IM10 can occur initiated by two H abstraction modes: $\mathrm{H}$ abstraction with ortho-carbon $\mathrm{Cl}$ substitute (in Figure 3) and $\mathrm{H}$ abstraction with meta-carbon $\mathrm{Cl}$ substitute (in Figure 4). The potential barriers $(\Delta E)$ and reaction heats $(\Delta H)$ are calculated at the MPWB1K/6-311+G(3df,2p)//MPWB1K/6-31+G(d,p) level. In Figures 3, four PCN products (1,5-/1,6-/1,7-/1,8-DCNs) from six possible reaction pathways (pathways 11-16) are proposed for the subsequent reactions of IM10 initiated by $\mathrm{H}$ abstraction with ortho-carbon $\mathrm{Cl}$ substitute. All the six pathways start with $\mathrm{H}$ abstraction step by $\mathrm{H}, \mathrm{OH}$, and $\mathrm{Cl}$ radicals, followed by two three-member ring close steps (first/second 3-member ring close) and two 6-member ring form steps (first/second six-member ring form) and ended by the $\mathrm{H}$ elimination step. The rate-determining step for pathways 11-16 is also the first six-member ring form. Pathway 11 and pathway 12 have the same rate-determining step. (potential barrier 26.75 and $25.58 \mathrm{kcal} / \mathrm{mol}$ ). IM44 and IM45 are enantiomers that produce the same subsequent intermediate (IM49, IM50, IM52 and IM54). Pathways 13-16 have the same rate-determining step (potential barrier 26.90 and $25.77 \mathrm{kcal} / \mathrm{mol}$ ), and the differences of pathways $13-16$ occur in the last three elementary steps. The H elimination step in pathway 16 involves the highest barrier $(19.48 \mathrm{kcal} / \mathrm{mol})$ and is most endoergic $(7.86 \mathrm{kcal} / \mathrm{mol})$ than any elementary step in the last three elementary steps of pathways 13-16, e.g., pathways 13-15 (resulting in 1,5-/1,6-/1,7-DCNs) are thermodynamically favored compared with pathway 16 (resulting in 1,8-DCN). Thus, $1,8-\mathrm{DCN}$ is not the main product of subsequent reactions of IM10 in Figure 3. This agrees well with the experiment result that only trace amounts of 1,8-DCN were observed from 3-CP as precursor [32,33]. Comparing pathway 13-15 with pathways 11-12, all the five pathways occur via the same elementary steps, and potential barrier of rate-determining steps are closer. Thus pathways 11-15 are energetically competitive, resulting in the formation of 1,5-/1,6-/1,7-DCNs. The main products of the subsequent reactions of IM10 initiated $\mathrm{H}$ abstraction with ortho-carbon $\mathrm{Cl}$ substitute are 1,5-/1,6-/1,7-DCNs.

Figure 4 shows the subsequent reactions of IM1 0 starting at $\mathrm{H}$ abstraction with meta-carbon $\mathrm{Cl}$ substitute. In Figure 4, pathways 18, 20, 21, 22, 23, and 24 are homologous, which are ended with the H elimination step and contain the same six elementary steps as those mentioned above. The rate-determining step for pathways 18, 20,21, 22, 23, and 24 is the first six-member ring form step. Pathways 17 and 19 are similar. The second 6-member ring form and $\mathrm{Cl}$ elimination in pathways 17 and 19 is a concerted reaction occurring in a one-step. Thus pathways 17 and 19 involve five elementary steps: (1) H abstraction; (2) first 
three-member ring close; (3) first six-member ring form; (4) second three-member ring close; and (5) second six-member ring form and $\mathrm{Cl}$ elimination. The rate-determining step for pathways 17 and 19 is also the first 6-member ring form step. From Figure 4, pathways 17-20 occur via a pair of enantioners, denoted as IM59 and IM60, and the same rate-determining step (potential barrier 23.20 and $23.17 \mathrm{kcal} / \mathrm{mol}$ ); pathways 21-24 occur via a pair of enantioners (IM25 and IM26) and the identical rate-determining step (potential barrier 26.75 and $26.59 \mathrm{kcal} / \mathrm{mol}$ ). The rate-determining steps for pathways 17-20 require relative lower potential barrier than those of pathways 21-24. In addition, pathways 17 and 19 have one step less than pathways $18,20,21,22,23$, and 24. Thus, pathways 17 and 19 are energetically preferred than pathways 18, 20,21, 22, 23, and 24, i.e., pathways ended with $\mathrm{Cl}$ elimination are favored over those ended with $\mathrm{H}$ elimination, resulting in the formation of 2-MCN. The main product of the subsequent reactions of IM10 initiated $\mathrm{H}$ abstraction with meta-carbon $\mathrm{Cl}$ substitute is 2-MCN.

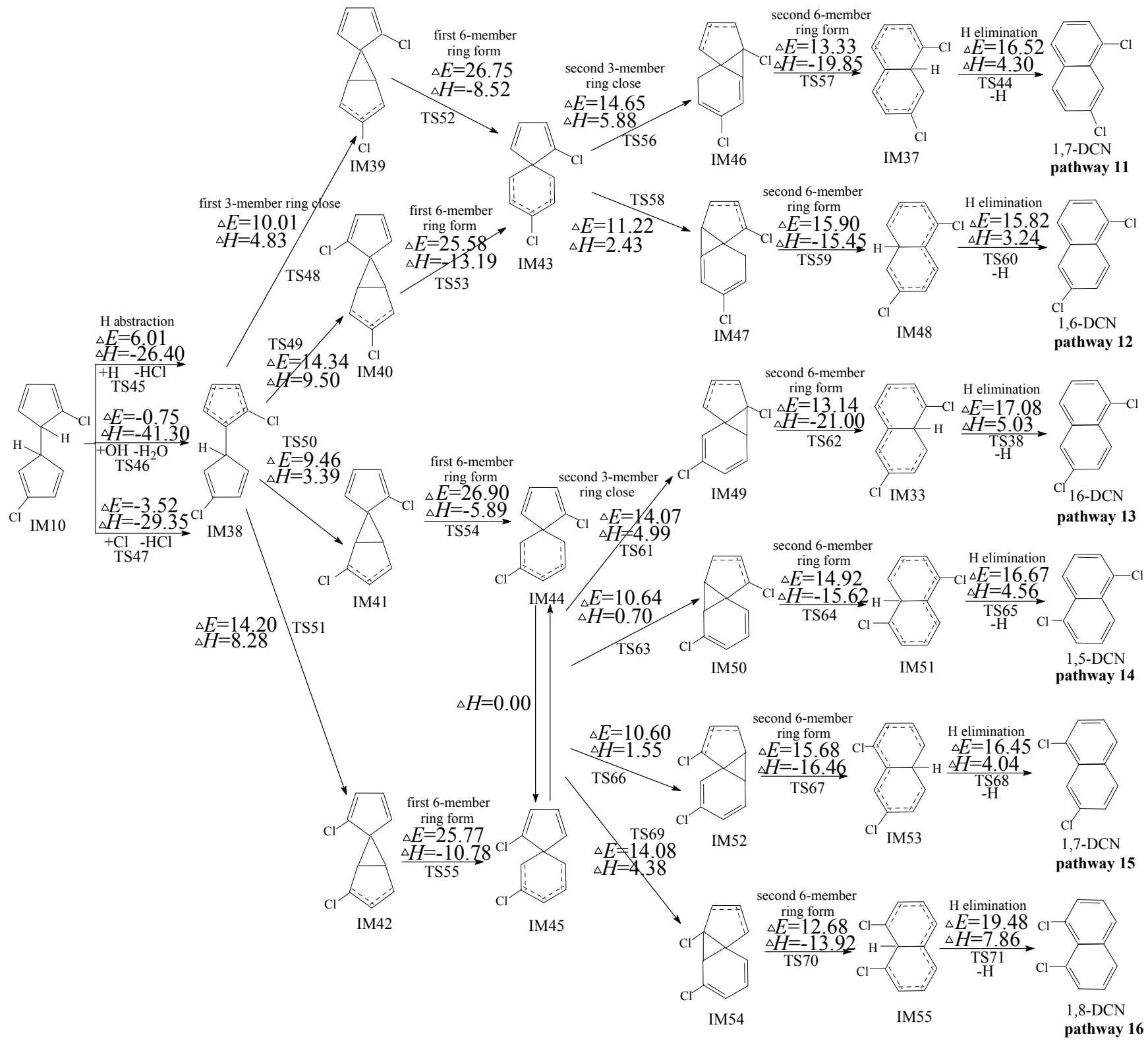

Figure 3. $\mathrm{PCN}$ formation routes embedded with the potential barriers $\Delta E$ (in $\mathrm{kcal} / \mathrm{mol}$ ) and reaction heats $\Delta H$ (in $\mathrm{kcal} / \mathrm{mol}$ ) from $\mathrm{IM} 10$ initiated $\mathrm{H}$ abstraction with ortho-carbon $\mathrm{Cl}$ substitute. $\Delta H$ is calculated at $0 \mathrm{~K}$. 


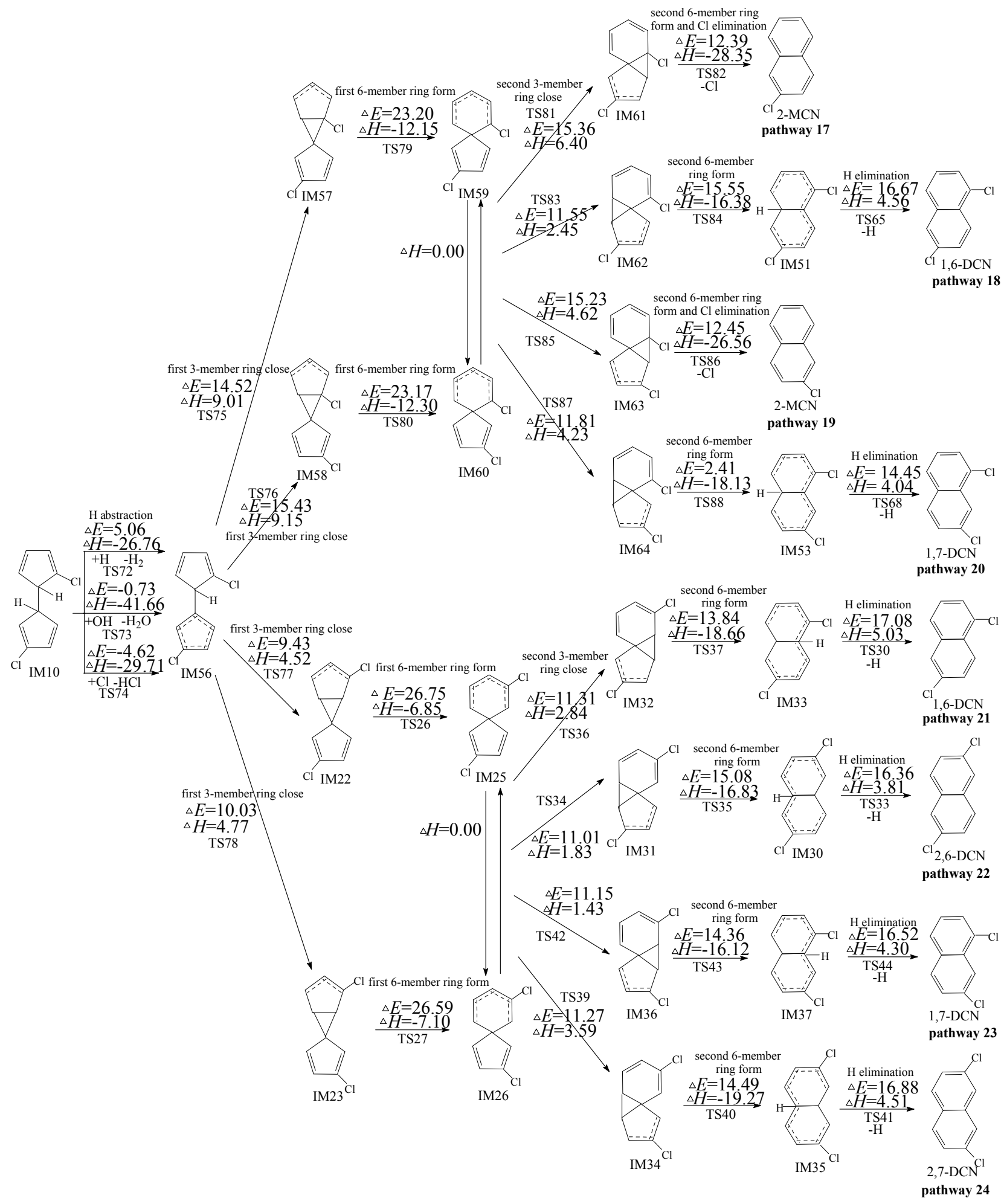

Figure 4. PCN formation routes embedded with the potential barriers $\Delta E$ (in $\mathrm{kcal} / \mathrm{mol}$ ) and reaction heats $\Delta H$ (in $\mathrm{kcal} / \mathrm{mol}$ ) from IM10 initiated $\mathrm{H}$ abstraction with meta-carbon $\mathrm{Cl}$ substitute. $\Delta H$ is calculated at $0 \mathrm{~K}$.

In Kim's mechanism, the chloro-dihydrofulvene occurs intramolecular rearrangement of 1,5-sigmatropic shifts of $\mathrm{H} / \mathrm{Cl}$ to the ortho-carbon of cyclopentadiene ring before ortho-carbon $\mathrm{H} / \mathrm{Cl}$ atom is abstracted by $\mathrm{H}, \mathrm{OH}$ and $\mathrm{Cl}$ radicals. However, this deduction has been refused in our previous study on PCN formation from 2-CP and 4-CP [47,48], owning to the high potential barrier of 1,5-sigmatropic shift step. 
Similarly, theoretical calculation of 1,5-sigmatropic H shift mechanism of IM10 is shown in Figure 5. Compared with the $\mathrm{H}$ direct abstraction routes in Figure 3, the $\mathrm{H}$ shift mode requires crossing a high barrier $(26.47 \mathrm{kcal} / \mathrm{mol})$ and is endothermic $(1.41 \mathrm{kcal} / \mathrm{mol})$. This reconfirms the conclusion that the direct $\mathrm{H}$ abstraction mechanism shown in Figure 3 is energetically favored over $\mathrm{H}$ shift mechanisms shown in Figure 5.

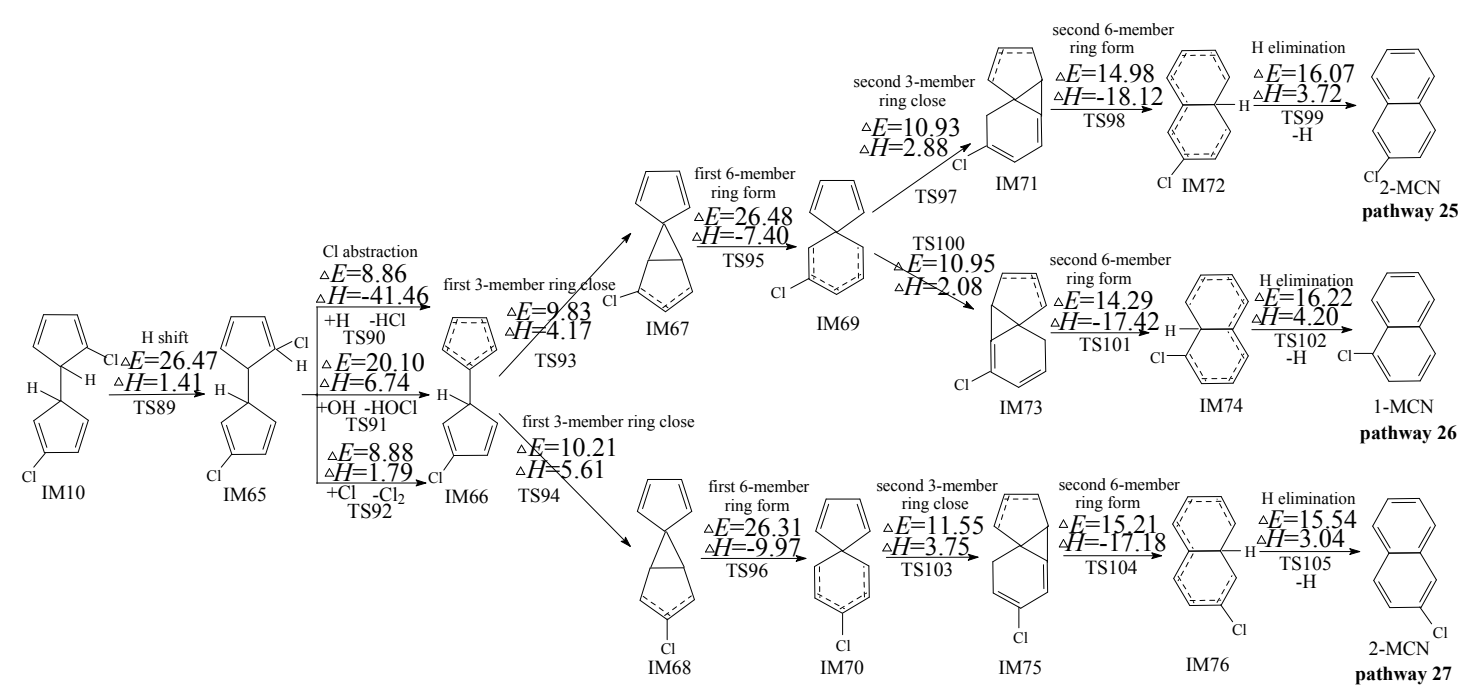

Figure 5. PCN formation routes from IM10 proposed by Kim [32,33], starting with H-shift step. These routes are embedded with the potential barriers $\Delta E$ (in $\mathrm{kcal} / \mathrm{mol}$ ) and reaction heats $\Delta H$ (in $\mathrm{kcal} / \mathrm{mol}) . \Delta H$ is calculated at $0 \mathrm{~K}$.

\subsection{Formation of PCNs from Subsequent Reactions of IM18}

Figures 6 shows formation of PCNs from subsequent reactions of IM18 embdded with the potential barriers $(\Delta E)$ and reaction heats $(\Delta H)$ at the MPWB1K/6-311+G(3df,2p)//MPWB1K/6-31+G(d,p) level. Eight possible reaction pathways (pathways 28-35) are proposed for the subsequent reactions of IM10 to form five PCNs (1-MCN and 1,5-/1,6-/1,7-/1,8-DCNs). From Figure 6, pathways 28, 29, 30, 31, 32, and 34 are alike, and they involve six elementary steps similar as the six-step pathways mentioned above (ended with $\mathrm{H}$ elimination step). Pathways 33 and 35 are homologous, and they contain five elementary steps similar as five-step pathways mentioned above (ended with a concerted second 6-member ring form and $\mathrm{Cl}$ elimination step). The rate-determine step for pathways $28-35$ is the first 6 -member ring form step. From Figure 6, pathways 28-31 have the same rate-determining step (potential barriers 26.90 and $25.77 \mathrm{kcal} / \mathrm{mol}$ ), and pathways $32-35$ have the identical rate-determining steps (potential barriers 22.76 and $22.35 \mathrm{kcal} / \mathrm{mol}$ ). The rate-determining step of pathway 32-35 require crossing lower potential barriers than those of pathway 28-31. In addition, pathway 33 and 35 have one step less than pathways $28,29,30,31,32$, and 34 . Thus, pathway 33 and 35 are favored over pathways 28, 29, 30, 31, 32, and 34 , resulting in the formation of naphthalene (1-MCN). This re-verifies the conclusions that pathways ended with $\mathrm{Cl}$ elimination are energetically preferred than those ended with $\mathrm{H}$ elimination. 1-MCN is the main PCN products of subsequent reactions of IM18. 


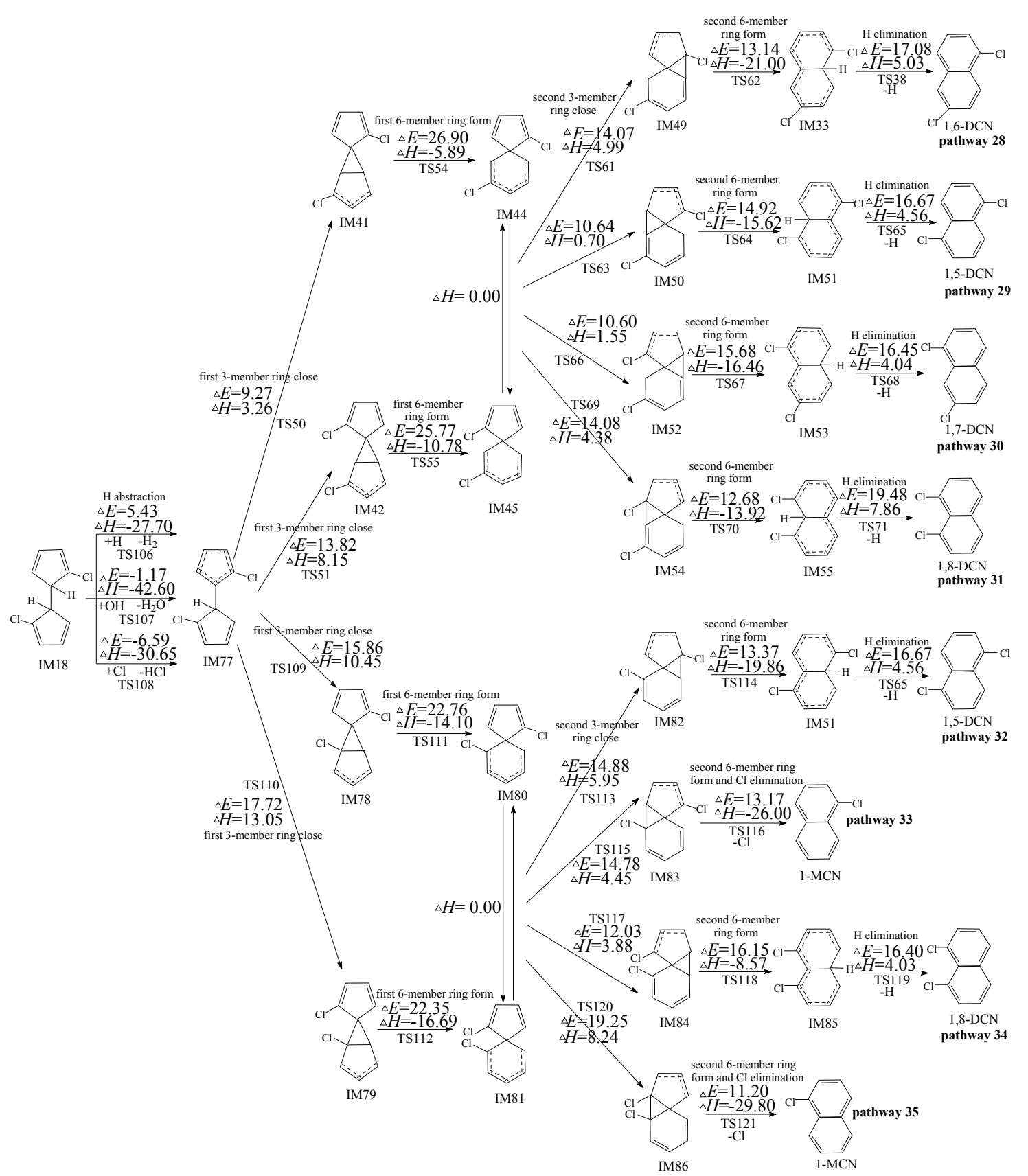

Figure 6. PCN formation routes from IM18 embedded with the potential barriers $\Delta E$ (in $\mathrm{kcal} / \mathrm{mol}$ ) and reaction heats $\Delta H$ (in $\mathrm{kcal} / \mathrm{mol}) . \Delta H$ is calculated at $0 \mathrm{~K}$.

\subsection{Comparison of PCN Formation Mechanism with the Experimental Observation}

To sum up Figures 1-6, the main PCN products from subsequent reactions of IM5 are 2,6-/2,7-DCNs in Figure 2; the main PCN products from subsequent reactions of IM10 are 1,5-/1,6-/1,7-/DCNs in Figure 3 and 2-MCN in Figure 4; the main PCN products from subsequent reactions of IM18 are 1-MCN in Figure 6. This can give a reasonbale explanation for the experimental observations that 3-CP produced nearly equal amounts of 1- and 2-MCN and nearly equal amounts of 1,5-/1,6-/1,7-DCNs and 2,6-/2,7-DCNs [32,33]. From both Kim's and Yang's experiments, the formation potential of MCN products are larger than that of DCN [27,32,33], which can be explained from three aspects. First, MCNs are formed from five elementary steps, with one step less than the DCNs formation. Secondly, the rate-determined steps of 
MCN formation pathways require crossing lower potential barriers than that of DCN formation pathways. Thirdly, more MCN products may come from the cross-reaction of phenoxy radicals with 3-CPR because CPs are easy to lose $\mathrm{Cl}$ atoms at high temperatures to form phenol, which was also detected in the Kim's experiments $[32,33]$. The formation of phenol can be reconfirmed by the large amount of $\mathrm{N}$ formation from 3-CP as a precursor in both Kim and Yang's experiments, which are not existent in our mechanism from dimerization of 3-CPRs. Presumably, $\mathrm{N}$ is formed from the cross-reaction of phenoxy radicals with 3-CPR with one $\mathrm{Cl}$ atom loss or the self-reaction of phenoxy radicals. Configurations of the transition states involved in one typical route of PCN formation of Figures 1-6 are depicted in Figure 7.

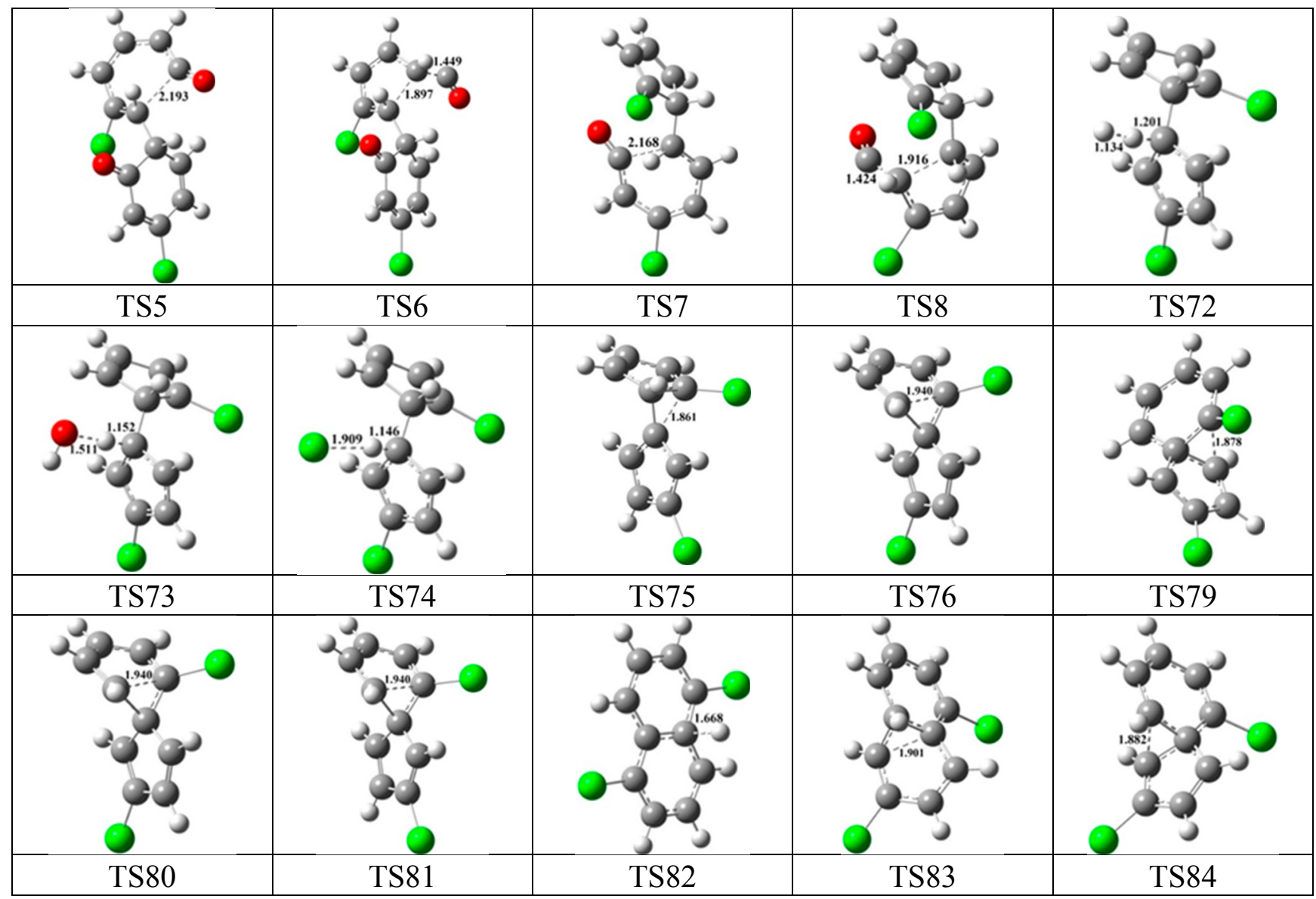

Figure 7. Configurations of the transition states involved in one typical route of PCN formation. Distances are in angstroms. Gray sphere, C; White sphere, H; Red sphere, O; Green sphere, $\mathrm{Cl}$. (For interpretation of the references to color in this figure legend, the reader is referred to the web version of this article.)

\subsection{Comparison of PCN Formation from 2-CP, 3-CP, and 4-CP}

Comparison of the formation of PCNs from the 3-CP with our previous studies of PCN formation from 2-CP and 4-CP precursors [47,48] shows that the position of chlorination affects each elementary step involved in the PCN formation. On the one hand, the isomer patterns of PCNs products are completely different from the three CPs. To sum up the relationship of PCN isomers with chlorinated dihydrofulvalene, it could be concluded that the ortho- $\mathrm{Cl}$ in dihydrofulvene would finally mainly located in the alpha position of naphthalene or be elimitated, but rarely located in beta position of naphthalene; 
the meta-Cl in dihydrofulvene would be finally mainly located in the beta position of naphthalene (could not be eliminated), rarely located in the alpha position of naphthalene. For 2-CP, it mainly forms dihydrofulvene with two ortho- $\mathrm{Cl}$ atoms. Thus, the finally main DCN production from 2-CP are DCNs with $\mathrm{Cl}$ atoms mainly located in the alpha position of naphthalene (1,5-/1,6-/1,7-DCNs), and the finally main MCN products from 2-CP is $\mathrm{MCN}$ eliminated one $\mathrm{Cl}$ and with other $\mathrm{Cl}$ located in the alpha position (1-MCN). For 4-CP, it mainly produces dihydrofulvene with two meta-Cl atoms. Thus the finally main DCN products from 4-CP are DCNs with $\mathrm{Cl}$ atoms maily located in the beta position of naphthalene and rarely located in the alpha position (2,6-/2,7-DCNs). For 3-CP, it can form three dihydrofulvenes: one is the dihydrofulvene with two ortho- $\mathrm{Cl}$, one is the dihydrofulvene with two meta- $\mathrm{Cl}$, and one is with one ortho and one meta-Cl atoms. Thus, 3-CP can, almost equally, produce $\mathrm{PCNs}$ with $\mathrm{Cl}$ atoms located in the alpha position (1,5-/1,6-/1,7-DCNs, 1-MCN) and $\mathrm{PCNs}$ with $\mathrm{Cl}$ atoms located in the beta position (2,6-/2,7-DCNs, 2-MCN). Hence, for MCNs, 2-CP mostly produced 1-MCN, 3-CP produced approximately equal amounts of 1-MCN and 2-MCN, and 4-CP can not produce MCN. For DCNs, 2-CP mostly produce 1,5-/1,6-/1,7-DCNs, 3-CP produced approximately equal amounts of 1,5-/1,6-/1,7-DCNs and 2,6-/2,7-DCNs, and 4-CP almost exclusively produced 2,6-/2,7-DCNs. These results agree well with Kim's observations $[32,33]$ and oppose the previous hypothesis of PCN formation mechanism via CO loss of CPRs to form the same chloro-CPDyl radical, which would produce the same PCNs products [26-29].

On the other hand, the position of chlorination also affects PCN formation potential. In Kim's experiment, 2-CP produced the lowest amount of PCNs [32,33]. This result could be explained by the higher potential barrier and less exothermic property of the phenolic-hydrogen abstraction of 2-CP than that of 3-CP and 4-CP, as mentioned in our previous studies [49,50], owning to intramolecular hydrogen bonding (enhancing the $\mathrm{O}-\mathrm{H}$ bond in 2-CP) and the inductive effect of the electron-withdrawing chlorine (weakening the $\mathrm{O}-\mathrm{H}$ bond in 4-CP) [49,50]. For example, the potential barrier of phenoxyl-hydrogen abstraction in 2-CP, 3-CP, and 4-CP by $\mathrm{OH}$ radical is $3.20,0.17$ and $-0.83 \mathrm{kcal} / \mathrm{mol}$, respectively, and the reaction heat of phenoxyl-hydrogen abstraction in 2-CP, 3-CP, and 4-CP by $\mathrm{OH}$ radical is -12.01 , -12.94 and $-15.13 \mathrm{kcal} / \mathrm{mol}[49,50]$. By In addition, dimerization of CPRs is barrierless and is the initial step of PCN formation. The dimerization of 3-CPRs $(-23.42,-23.25$ and $-23.60 \mathrm{kcal} / \mathrm{mol})$ is approximately $10 \mathrm{kcal} / \mathrm{mol}$ more exothermic than those of 2-CPRs $(-17.63$ and $-10.29 \mathrm{kcal} / \mathrm{mol})$ and 4-CPRs $(-16.20 \mathrm{kcal} / \mathrm{mol})[47,48]$. Thus, 3-CP have stronger PCN formation potential than that of 2-CP and 4-CP [46,47], which is consistent with the experimental result wherein 3-CP produced the highest PCN yield $[32,33]$.

\subsection{Rate Constant Calculations}

In the environmental field, mathematical models have been extensively applied in pollutants policy formulation, quantitative prediction, and risk analyses by predicting the potential sources and emissions of contaminant releases to the environment. For example, the PCN formation models and PCN controlling kinetic models can account for the potential outcomes of PCNs to the environment and the gaseous route in the production of PCNs in combustion and thermal processes. Among different parameters, the rate constants can be used as important input parameters for constructing and improving PCN mathematical models. However, owing to the limitation of experimental conditions and lack of the effective detection methods, it is difficult to measure, experimentally, the rate constants of the 
elementary reactions, especially the reactions involving the short-life radical intermediates in the formation of PCNs. In such a situation, an alternative method is to use the calculated rate constant or other dynamical information directly from quantum calculations of electronic structure, frequency, and energy.

In this paper, the rate constants of the crucial elementary reactions for the formation of PCNs from 3-CP were calculated by using canonical variational transition state theory (CVT) with small-curvature tunneling (SCT) contribution methods [51-54]. The CVT/SCT method is among the most promising current avenues of approach in theoretical chemical kinetics. The error correction of the kinetic calculation may be mainly from the SCT method [51-54]. The reliability and accuracy of the CVT/SCT method was verified in our recent studies [47-50,55-58]. For example, the CVT/SCT rate constants of $\mathrm{C}_{6} \mathrm{H}_{5} \mathrm{OH}+\mathrm{H} \rightarrow \mathrm{C}_{6} \mathrm{H}_{5} \mathrm{O}+\mathrm{H}_{2}$ and $\mathrm{C}_{6} \mathrm{H}_{5} \mathrm{OH}+\mathrm{OH} \rightarrow \mathrm{C}_{6} \mathrm{H}_{5} \mathrm{OH}+\mathrm{H}_{2} \mathrm{O}$ are in good agreement with the corresponding experimental values $[49,50]$, respectively. In addition, the CVT/SCT rate constants of (1)

are matches well with the available literature rate constant values $[59,60]$ for structurally-similar compounds

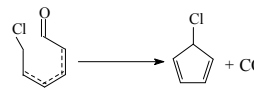

Actually, the CVT/SCT method has been successfully performed for the the rate calculations in our previous studies involved in the formation of $\mathrm{PCDD} /$ Fs from various $\mathrm{CP}$ precursors [55-58] and PCN formation from 2-CP and 4-CP precursors [47,48], and are clarified to be an efficient method to calculate the rate constants.

To be used more effectively, the CVT/SCT rate constants every $50 \mathrm{~K}$ from 600 to $1200 \mathrm{~K}$ were calculated, for elementary reactions involved in the thermodynamically preferred formation pathways of PCNs from 3-CP as precursor. The 600-1200 K covers the possible formation temperature range of PCN in municipal waste incinerators. The calculated CVT/SCT rate constants under different temperatures are fitted in the Arrhenius form, as shown in Table 1. The pre-exponential factors, the activation energies, and the rate constants can be obtained from these Arrhenius.

Table 1. Arrhenius formulas for crucial elementary reactions involved in the formation of PCNs from the 3-CP precursor over the temperature range of 600-1200 K (units are $\mathrm{s}^{-1}$ and $\mathrm{cm}^{3} \cdot$ molecule ${ }^{-1} \cdot \mathrm{s}^{-1}$ for unimolecular and bimolecular reactions, respectively).

\begin{tabular}{ll}
\hline Reactions & Arrhenius Formulas \\
\hline 3-TCP $+\mathrm{H} \rightarrow$ 3-MCPR $+\mathrm{H}_{2}$ & $k(\mathrm{~T})=\left(2.36 \times 10^{-12}\right) \exp (-6579.12 / \mathrm{T})$ \\
3-TCP $+\mathrm{OH} \rightarrow 3-\mathrm{MCPR}+\mathrm{H}_{2} \mathrm{O}$ & $k(\mathrm{~T})=\left(3.12 \times 10^{-12}\right) \exp (-1512.16 / \mathrm{T})$ \\
$3-\mathrm{TCP}+\mathrm{O}\left({ }^{3} \mathrm{P}\right) \rightarrow 3-\mathrm{MCPR}+$ & $k(\mathrm{~T})=\left(3.50 \times 10^{-11}\right) \exp (-4659.85 / \mathrm{T})$ \\
$\mathrm{OH}$ & $k(\mathrm{~T})=\left(4.06 \times 10^{13}\right) \exp (-20,030.86 / \mathrm{T})$ \\
$\mathrm{IM} 1 \rightarrow \mathrm{IM} 2$ via TS1 & $k(\mathrm{~T})=\left(9.43 \times 10^{9}\right) \exp (-24,696.87 / \mathrm{T})$ \\
$\mathrm{IM} 2 \rightarrow \mathrm{IM} 3+\mathrm{CO}$ via TS2 & $k(\mathrm{~T})=\left(5.13 \times 10^{13}\right) \exp (-20,235.56 / \mathrm{T})$ \\
$\mathrm{IM} 3 \rightarrow \mathrm{IM} 4$ via TS3 & $k(\mathrm{~T})=\left(2.51 \times 10^{11}\right) \exp (-23,661.43 / \mathrm{T})$ \\
$\mathrm{IM} 4 \rightarrow \mathrm{IM} 5+\mathrm{CO}$ via TS4 & $k(\mathrm{~T})=\left(3.64 \times 10^{13}\right) \exp (-20,292.91 / \mathrm{T})$ \\
$\mathrm{IM} 6 \rightarrow \mathrm{IM} 7$ via TS5 & $k(\mathrm{~T})=\left(1.68 \times 10^{11}\right) \exp (-25,390.77 / \mathrm{T})$ \\
$\mathrm{IM} 7 \rightarrow \mathrm{IM} 8+\mathrm{CO}$ TS6 & $k(\mathrm{~T})=\left(2.35 \times 10^{13}\right) \exp (-36,819.88 / \mathrm{T})$ \\
$\mathrm{IM} 8 \rightarrow \mathrm{IM} 9$ via TS7 & $k(\mathrm{~T})=\left(4.10 \times 10^{12}\right) \exp (-22,081.08 / \mathrm{T})$ \\
$\mathrm{IM} 9 \rightarrow \mathrm{IM} 10+\mathrm{CO}$ via TS8 & $k(\mathrm{~T})=\left(1.10 \times 10^{14}\right) \exp (-19,945.07 / \mathrm{T})$ \\
$\mathrm{IM} 6 \rightarrow \mathrm{IM} 11$ via TS9 & $k(\mathrm{~T})=\left(4.43 \times 10^{11}\right) \exp (-23,531.77 / \mathrm{T})$ \\
$\mathrm{IM} 11 \rightarrow \mathrm{IM} 12+\mathrm{CO}$ via TS10 & $k(\mathrm{~T})=\left(1.14 \times 10^{5}\right) \exp (-18,756.53 / \mathrm{T})$ \\
$\mathrm{IM} 12 \rightarrow \mathrm{IM} 13$ via TS11 &
\end{tabular}


Table 1. Cont.

\begin{tabular}{|c|c|}
\hline Reactions & Arrhenius Formulas \\
\hline $\mathrm{IM} 13 \rightarrow \mathrm{IM} 10+\mathrm{CO}$ via TS12 & $k(\mathrm{~T})=\left(5.95 \times 10^{9}\right) \exp (-22,995.33 / \mathrm{T})$ \\
\hline IM14 $\rightarrow$ IM15 via TS13 & $k(\mathrm{~T})=\left(5.70 \times 10^{13}\right) \exp (-19,945.04 / \mathrm{T})$ \\
\hline $\mathrm{IM} 15 \rightarrow \mathrm{IM} 16+\mathrm{CO}$ via TS14 & $k(\mathrm{~T})=\left(7.21 \times 10^{1 \circ}\right) \exp (-26,688.66 / \mathrm{T})$ \\
\hline IM16 $\rightarrow$ IM17 via TS15 & $k(\mathrm{~T})=\left(1.53 \times 10^{13}\right) \exp (-17,862.44 / \mathrm{T})$ \\
\hline $\mathrm{IM} 17 \rightarrow \mathrm{IM} 18+\mathrm{CO}$ via TS16 & $k(\mathrm{~T})=\left(3.25 \times 10^{11}\right) \exp (-23,917.06 / \mathrm{T})$ \\
\hline $\mathrm{IM} 10+\mathrm{H} \rightarrow \mathrm{IM} 56+\mathrm{H}_{2}$ via TS72 & $k(\mathrm{~T})=\left(6.92 \times 10^{-11}\right) \exp (-2926.10 / \mathrm{T})$ \\
\hline IM56 $\rightarrow$ IM57 via TS75 & $k(\mathrm{~T})=\left(1.37 \times 10^{12}\right) \exp (-7741.24 / \mathrm{T})$ \\
\hline IM56 $\rightarrow$ IM58 via TS76 & $k(\mathrm{~T})=\left(1.08 \times 10^{12}\right) \exp (-8010.75 / \mathrm{T})$ \\
\hline IM57 $\rightarrow$ IM59 via TS79 & $k(\mathrm{~T})=\left(1.67 \times 10^{13}\right) \exp (-11,934.50 / \mathrm{T})$ \\
\hline IM58 $\rightarrow$ IM60 via TS80 & $k(\mathrm{~T})=\left(6.96 \times 10^{13}\right) \exp (-11,934.96 / \mathrm{T})$ \\
\hline IM59/IM60 $\rightarrow$ IM61 via TS81 & $k(\mathrm{~T})=\left(2.24 \times 10^{11}\right) \exp (-9660.05 / \mathrm{T})$ \\
\hline $\mathrm{IM} 61 \rightarrow 2-\mathrm{MCN}+\mathrm{Cl}$ via TS82 & $k(\mathrm{~T})=\left(2.21 \times 10^{13}\right) \exp (-6651.99 / \mathrm{T})$ \\
\hline IM59/IM60 $\rightarrow$ IM63 via TS85 & $k(\mathrm{~T})=\left(3.02 \times 10^{12}\right) \exp (-7870.98 / \mathrm{T})$ \\
\hline $\mathrm{IM} 63 \rightarrow 2-\mathrm{MCN}+\mathrm{Cl}$ via TS86 & $k(\mathrm{~T})=\left(1.89 \times 10^{13}\right) \exp (-6658.32 / \mathrm{T})$ \\
\hline $\mathrm{IM} 18+\mathrm{H} \rightarrow \mathrm{IM} 77+\mathrm{H}_{2}$ via $\mathrm{TS} 106$ & $k(T)=\left(6.77 \times 10^{-13}\right) \exp (-3847.80 / T)$ \\
\hline IM77 $\rightarrow$ IM78 via TS109 & $k(\mathrm{~T})=\left(3.10 \times 10^{12}\right) \exp (-8185.85 / \mathrm{T})$ \\
\hline $\mathrm{IM} 77 \rightarrow \mathrm{IM} 79$ via TS110 & $k(\mathrm{~T})=\left(4.05 \times 10^{12}\right) \exp (-9142.08 / \mathrm{T})$ \\
\hline IM78 $\rightarrow$ IM80 via TS111 & $k(\mathrm{~T})=\left(1.70 \times 10^{13}\right) \exp (-11,846.10 / \mathrm{T})$ \\
\hline IM79 $\rightarrow$ IM81 via TS112 & $k(\mathrm{~T})=\left(1.82 \times 10^{13}\right) \exp (-11,683.31 / \mathrm{T})$ \\
\hline IM80/IM81 $\rightarrow$ IM83 via TS115 & $k(\mathrm{~T})=\left(2.73 \times 10^{12}\right) \exp (-7528.18 / \mathrm{T})$ \\
\hline $\mathrm{IM} 83 \rightarrow 1-\mathrm{MCN}+\mathrm{Cl}$ via $\mathrm{TS} 116$ & $k(\mathrm{~T})=\left(1.98 \times 10^{13}\right) \exp (-6998.83 / \mathrm{T})$ \\
\hline IM80/IM81 $\rightarrow$ IM86 via TS120 & $k(\mathrm{~T})=\left(7.40 \times 10^{11}\right) \exp (-8061.95 / \mathrm{T})$ \\
\hline $\mathrm{IM} 86 \rightarrow 1-\mathrm{MCN}+\mathrm{Cl}$ via $\mathrm{TS} 121$ & $k(\mathrm{~T})=\left(3.52 \times 10^{13}\right) \exp (-6073.38 / \mathrm{T})$ \\
\hline
\end{tabular}

\section{Experimental Section}

\subsection{Density Functional Theory}

All the calculations on the geometries, energies, frequencies for reactants, complexes, transition states, and products were determined using the Gaussian 09 program package [61]. The hybrid meta function MPWB1K was employed for the homogeneous gas-phase formation of PCNs from 3-CP precursor, which has uniformly good performance in quantum calculations of thermochemistry, thermochemical kinetics, hydrogen bonding, and weak interactions [62]. The reliability and accuracy of the MPWB1K method for the geometries, vibrational frequencies, and energy calculation of PCNs formation from CPs have been confirmed in our previous works on PCNs formation from 2-CP and 4-CP as precursors [47,48]. The geometries, vibrational frequencies, and the intrinsic reaction coordinate (IRC) calculations were carried out at the MPWB1K/6-31+G(d,p) level. The vibrational frequency calculations were used to determine the nature of minima and first-order saddle points and to provide the zero-point energy (ZPE) and the thermal contributions to the free energy of activation. The minimum energy path (MEP) was obtained by the IRC calculation to confirm that the transition state really connects to minima along the reaction path [63]. To obtain more reliable potential barriers and reaction heats, a more flexible basis set, $6-311+\mathrm{G}(3 \mathrm{df}, 2 \mathrm{p})$, was used to determine the single-point energies of the various species, based on the optimized geometries. All the relative energies quoted and discussed in this paper include ZPE corrections. 


\subsection{Kinetic Calculation}

The canonical variational transition state theory (CVT) with small-curvature tunneling (SCT) correction is an effective method to calculate the rate constants [50-54]. In this paper, the CVT/SCT method is used to calculate the rate constants of key elementary step involved in this study over a wide temperature range (600-1200 K) by using the Polyrate 9.7 program [64]. The level of tunneling calculation is the small curvature tunneling (SCT) [54] method, based on the centrifugal-dominant small-curvature semi-classical adiabatic ground-state approximation. The rotational partition functions were calculated classically, and the vibrational modes were treated as quantum-mechanically separable harmonic oscillators. The error of the kinetic calculation may be mainly from the small curvature tunneling (SCT) method, especially for the heavy-light-heavy (HLH) mass combination reactions. The large-curvature tunneling approximation may be especially desirable to model these kind of reactions in detail. Methods for large curvature cases have been developed [65], but they require more information about the potential energy surface than that was determined in the present study. Thus, the SCT approximation becomes to be an alternative to the large-curvature approximation. The new CD-SCSAG approximation for small-curvature tunneling is an improvement over the original SCSAG small-curvature method in that it accounts for the effect of mode-mode coupling on the extent of corner cutting through each vibrational degree of freedom orthogonal to the reaction path [66]. To calculate the rate constants, 40 non-stationary points near the transition state along the minimum energy path $(20$ points on the reactants side and 20 points on the product side) were selected for frequency calculations at the MPWB1K/6-31 + G(d,p) level. The parameters such as energy data, matrices of force constants, Hessian matrixes, coordinates of each stationary points, and unstationary points are obtained from the Gaussian 09 program output files and are input into the polyrate input files automatically by our self-compile program.

\section{Conclusions}

In this study, the mechanism of the homogeneous gas-phase formation of PCNs from the 3-CP precursor were investigated theoretically using DFT electronic structure theory at the MPWB1K/ $6-311+\mathrm{G}(3 \mathrm{df}, 2 \mathrm{p}) / / \mathrm{MPWB} 1 \mathrm{~K} / 6-31+\mathrm{G}(\mathrm{d}, \mathrm{p})$ level. The kinetic calculation was performed and the rate constants were calculated over the temeperature range of 600-1200 K using canonical variational transition-state (CVT) theory with the small curvature tunneling (SCT) contribution. The rate temperature formulas were fitted. The mechanism in this paper can well explain the experimental observation. The obtained rate constant can support more detailed input parameters for the PCN controlling and prediction models. This study is an ongoing work of our previous studies of PCN formation from 2-CP and 4-CP, so the effect of the position of chlorination on PCN formation were discussed. Four specific conclusions can be drawn:

(1) Dimerization of chlorophenoxy radicals (CPRs) contains three $\mathrm{CH} / \mathrm{CH}$ coupling modes, resulting in three chloro-dihydrofulvene. The formation pathways of the three chloro-dihydrofulvene are all energetically feasible.

(2) The subsequent reactions of chloro-dihydrofulvene contains two different pathwways. The pathways ended with $\mathrm{Cl}$ elimination are favored over those ended with $\mathrm{H}$ elimination. 
(3) Both 1-MCN and 2-MCN are the main MCN products from 3-CP precursor, and both 1,5-/1,6-/ 1,7-DCNs and 2,6-/2,7-DCNs are the main DCN products from 3-CP precursor. The formation potential of MCNs with one chlorine loss is larger than that of DCNs without chlorine loss.

(4) The position of chlorination in monochlorophenol affect both isomer patterns and formation potential of PCNs products.

\section{Supplementary Materials}

The imaginary frequencies, the zero-point energies and the total energies for the transition states involved in the formation of PCNs from the 3-CP precursor. Cartesian coordinates for the reactants, intermediates, transition states and products involved in PCN formation from 3-CP. Supplementary materials can be found at http://www.mdpi.com/1422-0067/16/09/20620/s1.

\section{Acknowledgments}

This work was supported by NSFC (National Natural Science Foundation of China, project Nos. 21337001, 21407096, 21477066), and the China Postdoctoral Science Foundation funded project (project Nos. 2014M551911, 2015T80719). The authors thank Donald G. Truhlar for providing the POLYRATE 9.7 program.

\section{Author Contributions}

Fei $\mathrm{Xu}$ designed and performed the mechanism calculations, then wrote the manuscript; Fei Xu, Xiangli Shi performed the kinetic calculation. Fei Xu, Xiangli Shi and Qingzhu Zhang all analyzed the data in the manuscript.

\section{Conflicts of Interest}

The authors declare no conflict of interest.

\section{References}

1. Ohura, T. Environmental behavior, sources, and effects of chlorinated polycyclic aromatic hydrocarbons. Sci. World J. 2007, 7, 372-380.

2. Ma, J.; Chen, Z.; Wu, M.; Feng, J.; Horii, Y.; Ohura, T.; Kannan, K. Airborne PM 2.5/PM 10-associated chlorinated polycyclic aromatic hydrocarbons and their parent compounds in a suburban area in Shanghai, China. Environ. Sci. Technol. 2013, 47, 7615-7623.

3. Ohura, T.; Morita, M.; Makino, M.; Amagai, T.; Shimoi, K. Aryl hydrocarbon receptor-mediated effects of chlorinated polycyclic aromatic hydrocarbons. Chem. Res. Toxicol. 2007, 20, 1237-1241.

4. Horii, Y.; Khim, J.S.; Higley, E.B.; Giesy, J.P.; Ohura, T.; Kannan, K. Relative potencies of individual chlorinated and brominated polycyclic aromatic hydrocarbons for induction of aryl hydrocarbon receptor-mediated responses. Environ. Sci. Technol. 2009, 43, 2159-2165.

5. Ohura, T.; Kitazawa, A.; Amagai, T.; Makino, M. Occurrence, profiles, and photostabilities of chlorinated polycyclic aromatic hydrocarbons associated with particulates in urban air. Environ. Sci. Technol. 2005, 39, 85-91. 
6. Kitazawa, A.; Amagai, T.; Ohura, T. Temporal trends and relationships of particulate chlorinated polycyclic aromatic hydrocarbons and their parent compounds in urban air. Environ. Sci. Technol. 2006, 40, 4592-4598.

7. Fu, J.; Suuberg, E.M. Thermochemical properties and phase behavior of halogenated polycyclic aromatic hydrocarbons. Environ. Toxicol. Chem. 2012, 31, 486-493.

8. Kido, T.; Sakakibara, H.; Ohura, T.; Guruge, K.S.; Kojima, M.; Hasegawa, J.; Iwamura, T.; Yamanaka, N.; Masuda, S.; Sakaguchi, M.; et al. Evaluation of chlorinated benz[a]anthracene on hepatic toxicity in rats and mutagenic activity in Salmonella typhimurium. Environ. Toxicol. 2013, 28, 21-30.

9. Colmsjo, A.; Rannug, A.; Rannug, U. Some chloro derivatives of polynuclear aromatic hydrocarbons are potent mutagens in Salmonella typhimurium. Mutat. Res. 1984, 135, 21-29.

10. Hu, J.; Jin, X.; Kunikane, S.; Terao, Y.; Aizawa, T. Transformation of pyrene in aqueous chlorination in the presence and absence of bromide ion: Kinetics, products, and their aryl hydrocarbon receptormediated activities. Environ. Sci. Technol. 2006, 40, 487-493.

11. Sankoda, K.; Nomiyama, K.; Yonehara, T.; Kuribayashi, T.; Shinohara, R. Evidence for in situ production of chlorinated polycyclic aromatic hydrocarbons on tidal flats: Environmental monitoring and laboratory scale experiment. Chemosphere 2012, 88, 542-547.

12. Sugiyama, H.; Katagiri, Y.; Kaneko, M.; Watanabe, T.; Hirayama, T. Chlorination of pyrene in soil components with sodium chloride under xenon irradiation. Chemosphere 1999, 38, 1937-1945.

13. Nilsson, U.L.; Oestman, C.E. Chlorinated polycyclic aromatic hydrocarbons: Method of analysis and their occurrence in urban air. Environ. Sci. Technol. 1993, 27, 1826-1831.

14. Ishaq, R.; Naf, C.; Yngve, Z.; Broman, D.; Jarnberg, U. PCBs, PCNs, PCDD/Fs, PAHs and Cl-PAHs in air and water particulate samples-Patterns and variations. Chemosphere 2003, 50, 1131-1150.

15. Sankoda, K.; Kuribayashi, T.; Nomiyama, K.; Shinohara, R. Occurrence and source of chlorinated polycyclic aromatic hydrocarbons (Cl-PAHs) in tidal flats of the ariake bay, Japan. Environ. Sci. Technol. 2013, 47, 7037-7044.

16. Brodskv, E.S.; Klyuev, N.A.; Soyfer, V.S.; Ibragimov, V.A. Chlorinated polycyclic aromatic hydrocarbons in the waste water of pulp and paper mills. Organohalogen Compd. 1999, 43, 127-130.

17. Altwicker, E.R. Relative rates of formation of polychlorinated dioxins and furans from precursor and de novo reactions. Chemosphere 1996, 33, 1897-1904.

18. Nielson, A.H.; Allard, A.S.; Hynning, P.A.; Rememberger, M. Distribution, fate and persistence of organochlorine compounds formed during production of bleached pulp. Toxicol. Environ. Chem. 1991, 30, 3-41.

19. Ohlenbusch, G.; Kumke, M.U.; Frimmel, F.H. Sorption of phenols to dissolved organic matter investigated by solid phase microextraction. Sci. Total Environ. 2000, 253, 63-74.

20. Zhu, J.; Chen, Y.F.; Dong, W.B.; Pan, X.X.; Hou, H.Q. Reaction mechanism of 3-chlorophenol with $\mathrm{OH}, \mathrm{H}$ in aqueous solution. J. Environ. Sci. 2003, 15, 55-59.

21. Her, T.M.; Lee, L.S.; Hsum, S.C. Solid-liquid equilibria of mixtures containing tert-butanol, $\mathrm{m}$-chlorophenol, and pchlorophenol and development of adductive crystallization processes. Fluid Phase Equilib. 2005, 237, 152-161.

22. Hazardous Substance Fact Sheet. Available online: http://nj.gov/health/eoh/rtkweb/documents/ fs/0402.pdf (accessed on 31 August 2015). 
23. Olie, K.; Vermeulen, P.L.; Hutzinger, O. Chlorodibenzo-p-dioxins and chlorodibenzofurans are trace components of fly ash and flue gas of some incinerators in the Netherlands. Chemosphere 1977, 6, 455-459.

24. Eiceman, G.A.; Clement, R.E.; Karasek, F.W. Analysis of fly ash from municipal incinerators for trace organic compounds. Anal. Chem. 1979, 51, 2343-2350.

25. Imagawa, T.; Takeuchi, M. Relation between isomer compositions of polychlorinated naphthalens and congener compositions of PCDDs/PCDFs from incinerators. Organohalogen Compd. 1995, 23, 487-490.

26. Akki, U.; Mulholland, J.A. Gas-phase formation of dioxin and other aromatic products from 2,6-dichlorophenol pyrolysis. Organohalogen Compd. 1997, 31, 475-479.

27. Yang, Y.; Mulholland, J.A.; Akki, U. Formation of furans by gasphase reactions of chlorophenols. Proc. Combust. Inst. 1998, 27, 1761-1768.

28. Evans, C.S.; Dellinger, B. Mechanisms of dioxin formation from the high-temperature pyrolysis of 2-chlorophenol. Environ. Sci. Technol. 2003, 37, 1325-1330.

29. Evans, C.S.; Dellinger, B. Mechanisms of dioxin formation from the high-temperature oxidation of 2-chlorophenol. Environ. Sci. Technol. 2005, 39, 122-127.

30. Barber, J.L.; Thomas, G.O.; Bailey, R.; Kerstiens, G.; Jones, K.C. Exchange of Polychlorinated Biphenyls (PCBs) and Polychlorinated Naphthalenes (PCNs) between Air and a Mixed Pasture Sward. Environ. Sci. Technol. 2004, 38, 3892-3900.

31. Phan, D.N.C.; Jansson, S.; Marklund, S. Effects of regional differences in waste composition on the thermal formation of polychlorinated aromatics during incineration. Chemosphere 2013, 93, $1586-1592$.

32. Kim, D.H.; Mulholland, J.A. Temperature-dependent formation of polychlorinated naphthalenes and dihenzofurans from chlorophenols. Environ. Sci. Technol. 2005, 39, 5831-5836.

33. Kim, D.H.; Mulholland, J.A.; Ryu, J.Y. Formation of polychlorinated naphthalenes from chlorophenols. Proc. Combust. Inst. 2005, 30, 1245-1253.

34. Kim, D.H.; Mulholland, J.A.; Ryu, J.Y. Chlorinated naphthalene formation from the oxidation of dichlorophenols. Chemosphere 2007, 67, S135-S143.

35. Cypres, R.; Bettens, B. La formation de la plupart des composes aromatiques produits lors de la pyrolyse du phenol, ne fait pas intervenir le carbone porteur de la fonction hydroxyle. Tetrahedron 1975, 31, 359-365.

36. Manion, J.A.; Louw, R. Rates, products, and mechanisms in the gas-phase hydrogenolysis of phenol between 922 and 1175 K. J. Phys. Chem. 1989, 3, 3563-3574.

37. Nich, M.; Marinov, M.J.; Castaldi, C.F.M.; Wing, T. Aromatic and polycyclic aromatic hydrocarbon formation in a premixed propane flame. Combust. Sci. Technol. 1997, 128, 295-342.

38. Friderichsen, A.V.; Shin, E.J.; Evans, R.J.; Nimlos, M.R.; Dayton, D.C.; Ellison, G.B. The pyrolysis of anisole $\left(\mathrm{C}_{6} \mathrm{H}_{5} \mathrm{OCH}_{3}\right)$ using a hyperthermal nozzle. Fuel 2001, 80, 1747-1755.

39. Lu M.M; Mulholland, J.A. PAH growth from the pyrolysis of CPD, indene and naphthalene mixture. Chemosphere 2004, 55, 605-610.

40. Kim, D.H.; Mulholland, J.A. Wang, D.; Violi, A. Pyrolytic hydrocarbon growth from cyclopentadiene. J. Phys. Chem. A 2010, 114, 12411-12416. 
41. Melius, C.F.; Colvin, M.E.; Marinov, N.M.; Pitz, W.J.; Senkan, S.M. Reaction mechanisms in aromatic hydrocarbon formation involving the $\mathrm{C}_{5} \mathrm{H}_{5}$ cyclopentadienyl moiety. Symp. Int. Combust.Proc. 1996, 26, 685-692.

42. Imagawa, T.; Lee, C.W. Correlation of polychlorinated naphthalenes with polychlorinated dibenzofurans formed from waste incineration. Chemosphere 2001, 44, 1511-1520.

43. Weber, R.; Iino, F.; Imagawa, T.; Takeuchi, M.; Sakurai, T.; Sadakata, M. Formation of PCDF, PCDD, PCB, and PCN in de novo synthesis from PAH: Mechanistic aspects and correlation to fluidized bed incinerators. Chemosphere 2001, 44, 1429-1438.

44. Oh, J.E.; Gullett, B.; Ryan, S.; Touati, A. Mechanistic relationships among PCDDs/Fs, PCNs, PAHs, CIPhs, and CIBzs in municipal waste incineration. Environ. Sci. Technol. 2007, 41, 4705-4710.

45. McIntosh, G.J.; Russell, D.K. Role of hydrogen abstraction acetylene addition mechanisms in the formation of chlorinated naphthalenes. 1. A quantum chemical investigation. J. Phys. Chem. A 2014, 118, 12192-12204.

46. McIntosh, G.J.; Russell, D.K. Role of hydrogen abstraction acetylene addition mechanisms in the formation of chlorinated naphthalenes. 2. kinetic modeling and the detailed mechanism of ring closure. J. Phys. Chem. A 2014, 118, 12205-2220.

47. Xu, F.; Zhang, R.M.; Li, Y.F.; Zhang, Q.Z.; Wang, W.X. Mechanistic and kinetic studies on homogeneous gas-phase formation of 2-chlorophenol as precursor. Int. J. Mol. Sci. 2015, reviesed version review.

48. Xu, F.; Zhang, R.M.; Li, Y.F.; Zhang, Q.Z. Homogeneous gas-phase formation of polychlorinated naphthalene from dimerization of 4-CPRs and cross-condensation of PhR with 4-CPR: Mechanism and kinetics Study. Comput. Theor. Chem. 2015, reviesed version review.

49. Zhang, Q.Z.; Qu, X.H.; Xu, F.; Shi, X.Y.; Wang, W.X. Mechanism and thermal rate constants for the complete series reactions of chlorophenols with H. Environ. Sci. Technol. 2009, 43, 4105-4112.

50. Xu, F.; Wang, H.; Zhang, Q.Z.; Zhang, R.X.; Qu, X.H.; Wang, W.X. Kinetic properties for the complete series reactions of chlorophenols with $\mathrm{OH}$ radicals-relevance for dioxin formation. Environ. Sci. Technol. 2010, 44, 1399-1404.

51. Baldridge, M.S.; Gordon, R.; Steckler, R.; Truhlar, D.G. Ab initio reaction paths and direct dynamics calculations. J. Phys. Chem. 1989, 93, 5107-5119.

52. Gonzalez-Lafont, A.; Truong, T.N.; Truhlar, D.G. Interpolated variational transition-state theory: Practical methods for estimating variational transition-state properties and tunneling contributions to chemical reaction rates from electronic structure calculations. J. Chem. Phys. 1991, 95, 8875-8894.

53. Garrett, B.C.; Truhlar, D.G. Generalized transition state theory. Classical mechanical theory and applications to collinear reactions of hydrogen molecules. J. Phys. Chem. 1979, 83, 1052-1079.

54. Fernandez-Ramos, A.; Ellingson, B.A.; Garret, B.C.; Truhlar, D.G. Variational transition state theory with multidimensional tunneling. In Reviews in Computational Chemistry; Lipkowitz, K.B., Cundari, T.R., Eds.; Wiley-VCH: Hoboken, NJ, USA, 2007.

55. Zhang, Q.Z.; Li, S.Q.; Qu, X.H.; Shi, X.Y.; Wang, W.X. A quantum mechanical study on the formation of PCDD/Fs from 2-chlorophenol as precursor. Environ. Sci. Technol. 2008, 42, 7301-7308.

56. Qu, X.H.; Wang, H.; Zhang, Q.Z.; Shi, X.Y.; Xu, F.; Wang, W.X. Mechanistic and kinetic studies on the homogeneous gas-phase formation of PCDD/Fs from 2,4,5-trichlorophenol. Environ. Sci. Technol. 2009, 43, 4068-4075. 
57. Xu, F.; Yu, W.N.; Gao, R.; Zhou, Q.; Zhang, Q.Z.; Wang, W.X. Dioxin formations from the radical/radical cross-condensation of phenoxy radicals with 2-chlorophenoxy radicals and 2,4,6-trichlorophenoxy radicals. Environ. Sci. Technol. 2010, 44, 6745-6751.

58. Xu, F.; Yu, W.N.; Zhou, Q.; Gao, R.; Sun, X.Y.; Zhang, Q.Z.; Wang, W.X. Mechanism and direct kinetic study of the polychlorinated dibenzo-p-dioxin and dibenzofuran formations from the radical/radical cross-condensation of 2,4-dichlorophenoxy with 2-chlorophenoxy and 2,4,6-trichlorophenoxy. Environ. Sci. Technol. 2011, 45, 643-650.

59. Colussi, A.; Zabel, F.; Benson, S.W. The very low-pressure pyrolysis of phenyl ethyl ether, phenyl allyl ether, and benzyl methyl ether and the enthalpy of formation of the phenoxy radical. Int. J. Chem. Kinet. 1977, 9, 161-178.

60. Lin, C.Y.; Lin, M.C. Thermal decomposition of methyl phenyl ether in shock waves: The kinetics of phenoxy radical reactions. J. Phys. Chem. 1986, 90, 425-431.

61. Frisch, M.J.; Trucks, G.W.; Schlegel, H.B.; Scuseria, G.E.; Robb, M.A.; Cheeseman, J.R.; Scalmani, G.; Barone, V.; Mennucci, B.; Petersson, G.A.; et al. Gaussian 09, Revision A.02; Gaussian, Inc.: Wallingford, CT, USA, 2009.

62. Zhao, Y.; Truhlar, D.G. Hybrid meta density functional theory methods for therochemistry, thermochemical kinetics, and noncovalent interactions: The MPW1B95 and MPWB1K models and comparative assessments for hydrogen bonding and van der waals interactions. J. Phys. Chem. A 2004, 108, 6908-6918.

63. Fukui, K. The path of chemical reactions-the IRC approach. Acc. Chem. Res. 1981, 14, 363-368.

64. Corchado, J.C.; Chuang, Y.Y.; Fast, P.L.; Villa, J.; Hu, W.P.; Liu, Y.P.; Lynch, G.C.; Nguyen, K.A.; Jackels, C.F.; Melissas, V.S.; et al. POLYRATE Version 9.7; University of Minnesota: Minneapolis, Minnesota, MN, USA, 2007.

65. Garrett, B.C.; Truhlar, D.G.; Wagner, A.F.; Dunning, T.H., Jr. Variational transition state theory and tunneling for a heavy-light-heavy reaction using an $a b$ initio potential energy surface. ${ }^{37} \mathrm{Cl}+\mathrm{H}(\mathrm{D}){ }^{35} \mathrm{Cl} \rightarrow \mathrm{H}(\mathrm{D}){ }^{37} \mathrm{Cl}+{ }^{35} \mathrm{Cl}$. J. Chem. Phys. 1983, 78, 4400-4413.

66. Skodje, R.T.; Truhlar, D.G.; Garrett, B.C. Vibrationally adiabatic models for reactive tunneling. J. Chem. Phys. 1982, 77, 5955-5976.

(C) 2015 by the authors; licensee MDPI, Basel, Switzerland. This article is an open access article distributed under the terms and conditions of the Creative Commons Attribution license (http://creativecommons.org/licenses/by/4.0/). 